\title{
Redescription and generic placement of Neopamera mumfordi (Van Duzee, 1935) and Remaudiereana castanea (Van Duzee, 1935) (Hemiptera: Heteroptera: Lygaeoidea: Rhyparochromidae)
}

\author{
PABLO M. DELLAPÉ ${ }^{(1)(2)} \&$ M. B. MALIPATIL ${ }^{(3)(4)}$ \\ (1) División Entomología, Facultad de Ciencias Naturales y Museo, Universidad Nacional de La Plata, Paseo del Bosque s/n, \\ B1900FWA, La Plata,Argentina.E-mail:pdellape@fcnym.unlp.edu.ar \\ (2) Consejo Nacional de Investigaciones Científicas y Técnicas, Argentina (CONICET) \\ (3) Department of Primary Industries, Knoxfield Centre, Private Bag 15, Ferntree Gully Delivery Centre, Vic. 3156, Australia. \\ E-mail: mallik.malipatil@dpi.vic.gov.au \\ ${ }^{(4)}$ La Trobe University, Bundoora, Vic. 3086, Australia.
}

\begin{abstract}
A new genus, Neocnemodus gen. nov., is erected to accommodate Neopamera mumfordi (Van Duzee) from the Marquesas Islands; the species is redescribed and illustrated, and its relationships with the genera Cnemodus Herrich-Schaeffer and Andercnemodus Brailovsky \& Cervantes-Peredo are analysed. Another Marquesas Island myodochine species, Remaudiereana castanea (Van Duzee), is redescribed, illustrated, and its generic placement discussed.
\end{abstract}

Key words: Myodochini, Marquesas, new genus, generic placement

\section{Introduction}

The worldwide distributed Myodochini is among the most diverse of the 14 tribes of Rhyparochromidae (Dellapé \& Henry 2010). The tribe is more diverse in the Neotropical Region, where about one half of the genera occur. Only six genera are known from the Pacific Oceanic islands: Remaudiereana Hoberlandt, Pamerarma Malipatil, Paromius Fieber, Gyndes Stål, Pseudopachybrachius Malipatil, and Horridipamera Malipatil (Harrington 1980).

Van Duzee (1932) described Ptochiomera caeca in "New Hemiptera Heteroptera from the Marquesas," and stated that at first he considered it a brachypterous form of Ptochiomera castanea, which he described in the same paper: "At first I was inclined to consider this a brachypterous form of castanea." Van Duzee (1935) proposed Ptochiomera mumfordi as a replacement name for P. caeca, as this was preoccupied.

Scudder (1970) transferred both species to Pachybrachius Hahn without any explanation. Harrington (1980) raised from synonymy the genus Remaudiereana Hoberlandt (synonymized with Pachybrachius by Malipatil, 1978) and included 18 species, including $P$. castanea. In the same paper, the related P. mumfordi was transferred from Pachybrachius to the newly described genus Neopamera, and thus P. mumfordi was the only non-American species. Neopamera has been lately proven to be a highly polyphyletic genus (Dellapé 2005, 2008).

In this contribution we provide an illustrated redescription of the species $N$. mumfordi, with the view to provide detailed justification for its placement in a new monotypic genus Neocnemodus gen. nov. A description of the genus, along with notes on its comparison with other related genera, Cnemodus Herrich-Schaeffer and Andercnemodus Brailovsky \& Cervantes-Peredo, is provided.

Additionally, a redescription and illustrations of another Marquesas Island species, Remaudiereana castanea, and a discussion on its systematic position is given. 


\section{Materials and methods}

Composite automontage images of all habitus and other details of the body and genitalia characters were obtained with a M205C Leica microscope and camera using the Leica Application Suite software (version 3.4.0).

The specimens studied belong to the Bishop Museum, Honololu, USA (BPBM). Measurements are in millimetres.

\section{Taxonomy}

Genus Neocnemodus gen. nov. (Figs. 1-11)

Type species: Ptochiomera mumfordi Van Duzee, 1935

Monotypic.

Diagnosis: This genus can be distinguished from other genera with species exhibiting coleopteroid forms and lacking ocelli, such as Cnemodus and Andercnemodus, by its rather broad V-shaped pronotal collar, the strongly punctate body, and the scalloping of abdominal sterna; and from the former genus by the reduced evaporative area and the forefemoral spines reduced and arranged in single inner row; and from Andercnemodus by the enclosed mesepimeron, and the non-crenate corial margin.

\section{Description:}

Head (Figs. 1-3) lacking ocelli; bucculae gradually narrowed posterior and joined in a broad "V" at about 1/3 from base of head (Fig. 4), then as fine indistinct carina extending to base of head.

Pronotum (Figs. 1-3) almost glabrous, flattened, deeply, sparsely punctate all over, punctures on anterior lobe area particularly shallower and less conspicuous than those on collar and posterior lobe area; collar well delimited by a punctate sulcus, wider medially, almost to a peculiar median V-shape (Figs. 1-2); posterior pronotal lobe delimited by a shallow transverse impression. Thoracic sterna with a median keel. Thoracic pleura strongly punctate. Mesepimeron enclosed. Metathoracic scent gland evaporatorium reduced (Fig. 3). Hemelytra (Fig. 6) coleopteroid, clavus and corium fused, membrane greatly reduced to a narrow flap, posterior margin almost truncate, covered with 4 almost complete rows (first 3 on "claval area," $4^{\text {th }}$ row on inner margin of "corial area.") Hind wings absent. Legs with profemora enlarged and armed with 3 small spines on distal half on inner row. Abdomen (Figs. 7-8) with almost entire anterior margins of abdominal sterna II strongly, III slightly, and IV weakly scalloped. Spermatheca (Fig. 11) long, 4-partite.

\section{Discussion:}

In the key to the genera of Myodochini by Harrington (1980), this genus, because it lacks ocelli, runs to couplet 6 with Cnemodus (with two Nearctic species), and also resembles the recently described monotypic Andercnemodus (Mexico) (Brailovsky \& Cervantes-Peredo 2011). These three genera share a combination of characters which are related to brachypterous, possibly flightless, morphs: absence of ocelli, and the reduction of the hemelytra and the membrane to variable degree; and a V-shaped buccula. Additionally, this genus shares with Andercnemodus the reduced profemoral armature, with only a few minute spines on its distal $1 / 2$ length, and the reduced evaporative area of the metathoracic scent gland; and with Cnemodus in its enclosed mesepimeron and the non-crenate margin of the corium.

According to Harrington (1980), the strongly punctate pronotum, hemelytra, and thoracic pleura, and the scalloping of abdominal sterna, are indicative of a primitive taxon.

The above mentioned characters together with the peculiar median broad V-shaped pronotal collar (only Paromius exhibits a similar condition); the flattened pronotum, and the keeled sterna, enable distinguishing this genus from the others.

Since many of the generic diagnostic characters in Myodochini are based on males, the female holotype, the only known specimen available, does not allow us to make a robust generic characterization. Only future studies, when more specimens, particularly of males, become available, will be able to provide a detailed analysis of the relationships of these myodochine taxa. 
Neocnemodus mumfordi (Van Duzee 1935) comb. nov. (Figs. 1-11)

Ptochiomera caeca Van Duzee, 1932: 187

Ptiochiomera (sic) mumfordi Van Duzee, 1935: 174 (new name for Ptochiomera caeca Van Duzee 1932, preocupped)
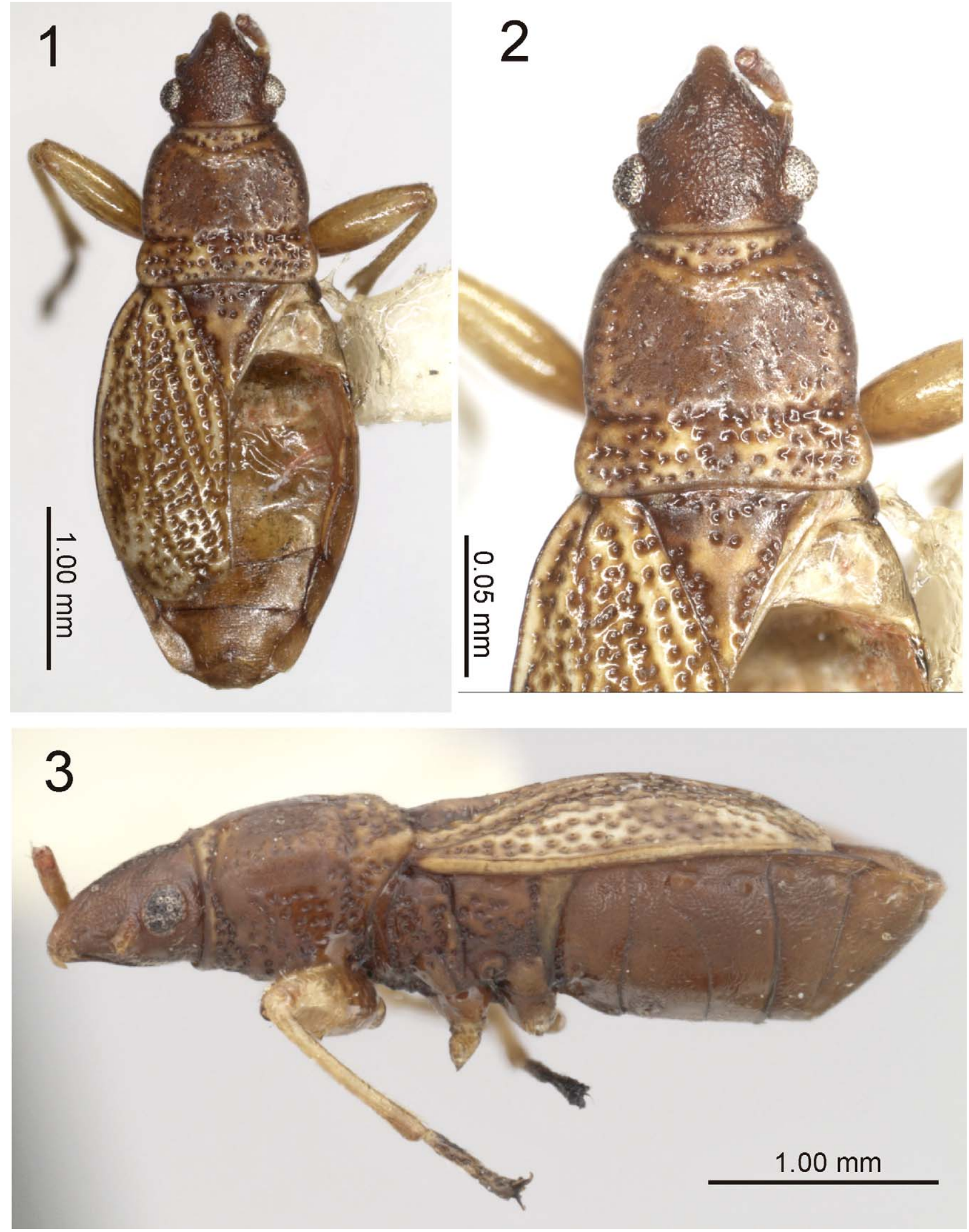

FIGURES 1-3. Neocnemodus mumfordi, holotype female: (1) body, dorsal view; (2) body, anterior part; (3) body, lateral view. Ptochiomera mumfordi: Slater, 1964: 1168 
Pachybrachius mumfordi: Scudder, 1970: 102

Neopamera mumfordi: Harrington, 1980: 107; Slater \& O’Donnell, 1995: 151

\section{Specimen Examined:}

Holotype: +, Ptochiomera caeca Van Duzee, "Type caeca," "Marquesas Islands," "Oomu Nukuhiva," "3400 ft., XI-II-29," "Mumford \& Adamson," "Pacific Entomological Survey," "beating on Weinmania parviflora ." Labium, right hemelytra, left posterior leg, and left scapus are glued on a separate card. Left median leg and right posterior leg, and distal 3 segments of both antennae missing. Genitalia dissected and preserved in glycerine in vial attached to pin under the specimen. Specimen deposited in B.P. Bishop Museum, Honolulu.

\section{Redescription:}

Female holotype (Figs. 1-11):

Body and appendages generally brown to light brown. Body dorsally and ventrally subshiny, length 4.2, maximum width 1.60 (Fig. 1).
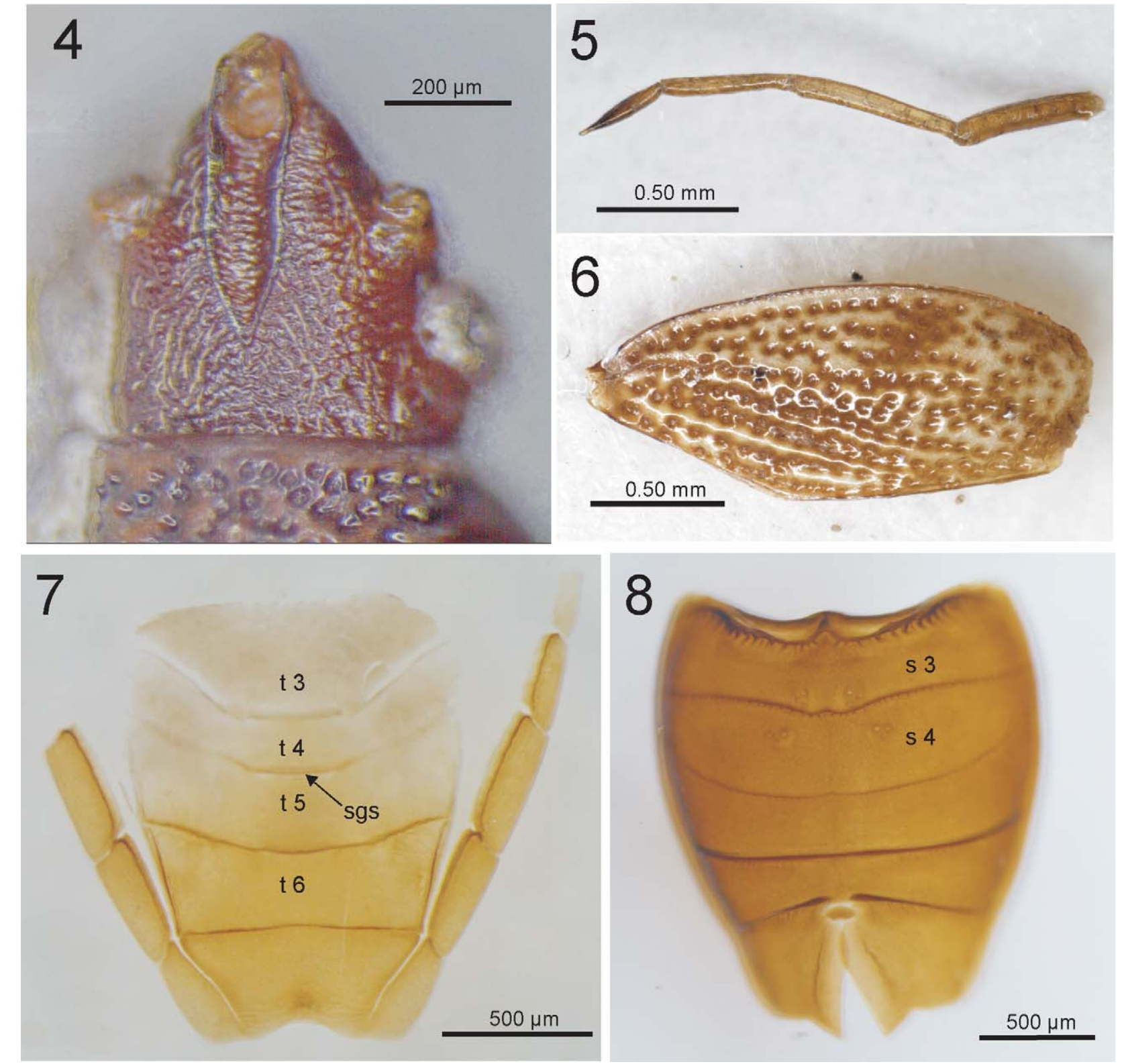

FIGURES 4-8. Neocnemodus mumfordi, holotype female: (4) head, ventral view; (5) labium; (6) hemelytra; (7) abdominal terga; (8) abdominal venter. Abbreviations: sgs, scent gland scar; t 3-t 6, terga 3-6; s 3, s 4, sterna 3, 4. 
Head (Figs. 1-3) covered with very short decumbent silvery setae, juga rounded, head length 0.68 , postocular distance 0.09 ; head width across eyes 0.74 , eyes relatively small, interocular space 0.50 . Labium (Fig. 5); length labial segments: I 0.56, II 0.62, III 0.45, IV 0.32. Length antennal segments, I 0.44, remaining segments missing.

Thorax. Pronotum (Figs. 1-3) length 0.91 (collar length medially 0.12 , anterior pronotal length without collar 0.53 , posterior pronotal length 0.26 ); anterior pronotal lobe width 0.99 , posterior pronotal lobe width 1.06 , collar width 0.64. Scutellum punctate, except on a raised Y-shaped carina, length 0.62 , width 0.50 . Hemelytra (Fig. 6) almost attaining posterior margin of sixth abdominal tergum, outer margin convex and narrowly explanate, posterior margin almost truncate and without a trace of membrane, inner margin straight, length 1.82, width 0.91 ; surface smooth, coarsely punctate, punctures spaced about one puncture width, inner area with 4 almost complete rows (first 3 on "claval area," $4^{\text {th }}$ row on inner margin of "corial area,") then irregular punctures except one regular row along outer margin. Legs with short sparse setae. Thoracic pleura shiny, coarsely punctate, glabrous, ostiolar peritreme rounded.

Abdomen with short decumbent, silvery setae; sterna not carinate medianly. Terga (Fig. 7) uniformly smooth and impunctate, terga of anterior segments lightly pigmented than those of posterior segments. Scent gland scars present between III-IV, IV-V and V-VI, those between III-IV about $1.25 \mathrm{X}$ wider that the posterior two, these subequals in width. Ovipositor (Figs. 9-10), $1^{\text {st }}$ ramus traversing to about $1 / 2$ length of $1^{\text {st }}$ gonapophysis, this gradually narrowed to a point apically; $2^{\text {nd }}$ gonapophysis spatulate, subapically narrowed, margins with sparse short bristles, 2 apical bristles longer and more prominent. Spermatheca (Fig. 11) long, 4-partite - short narrow basal part, sac-like subbasal part, coiled part with 12-17 coils, the basal coils narrow and uniform, apical bulb saccoid, indistinct.

Male. Unknown.

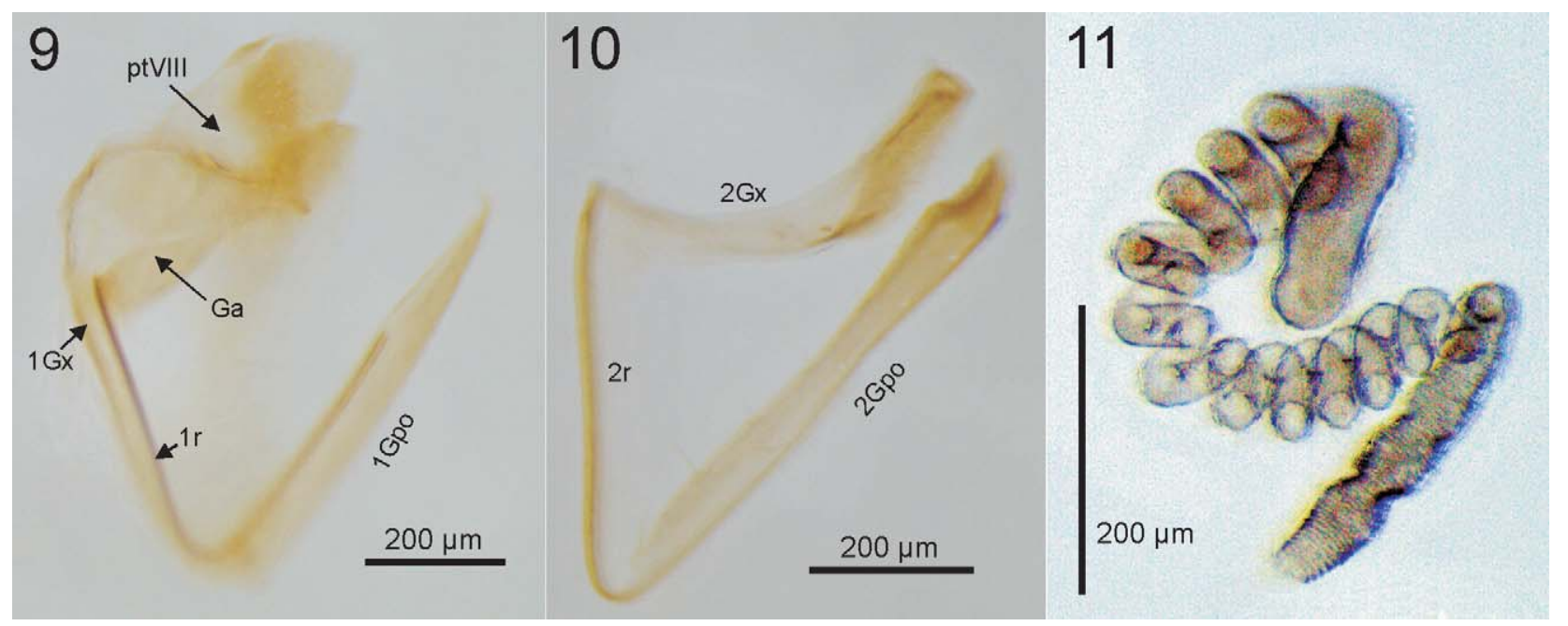

FIGURES 9-11. Neocnemodus mumfordi, holotype female: (9, 10) ovipositor; (11) spermatheca. Abbreviations: Ga, gonangulum; 1Gpo, 2Gpo, first and second gonapophysis; $1 \mathrm{Gx}, 2 \mathrm{Gx}$, first and second gonocoxa; ptVIII, eighth paratergite; 1r, $2 \mathrm{r}$, first and second ramus.

Comments: The female holotype is the only specimen known.

Distribution. Known only from Marquesas Islands.

\section{Remaudiereana castanea (Van Duzee 1935) (Figs. 12-17)}

Ptochiomera castanea Van Duzee, 1932: 186.

Ptochiomera castanea: Slater, 1964: 1167.

Pachybrachius castanea: Scudder, 1970: 102.

Remaudiereana castanea: Harrington, 1980: 92; Slater \& O’Donnell, 1995: 161. 


\section{Specimen examined:}

Holotype: đ̊, Vaiepoepo, Hiva Oa, VI-3-29, 2450 ft., Marquesas Islands, Metrosideros, Mumford\& Adamson, Pacific Entomological Survey, Type castanea, Ptochiomera castanea Van Duzee, Holotype N 603. Right posterior leg glued on the same card. Right antenna missing. Genitalia dissected and preserved in glycerine in vial attached to pin under the specimen. Specimen deposited in B.P. Bishop Museum, Honolulu.

\section{Redescription:}

Male holotype (Figs. 12-17):

General coloration light brown; head shiny reddish brown. Body length 3.95, maximum width 1,34 at level of claval commisure. Pronotum, scutellum and hemelytra sparsely pilose, with short silvery decumbent setae, pleurae and legs with abundant short silvery decumbent setae, sparser and shorter on abdomen (Fig. 12).

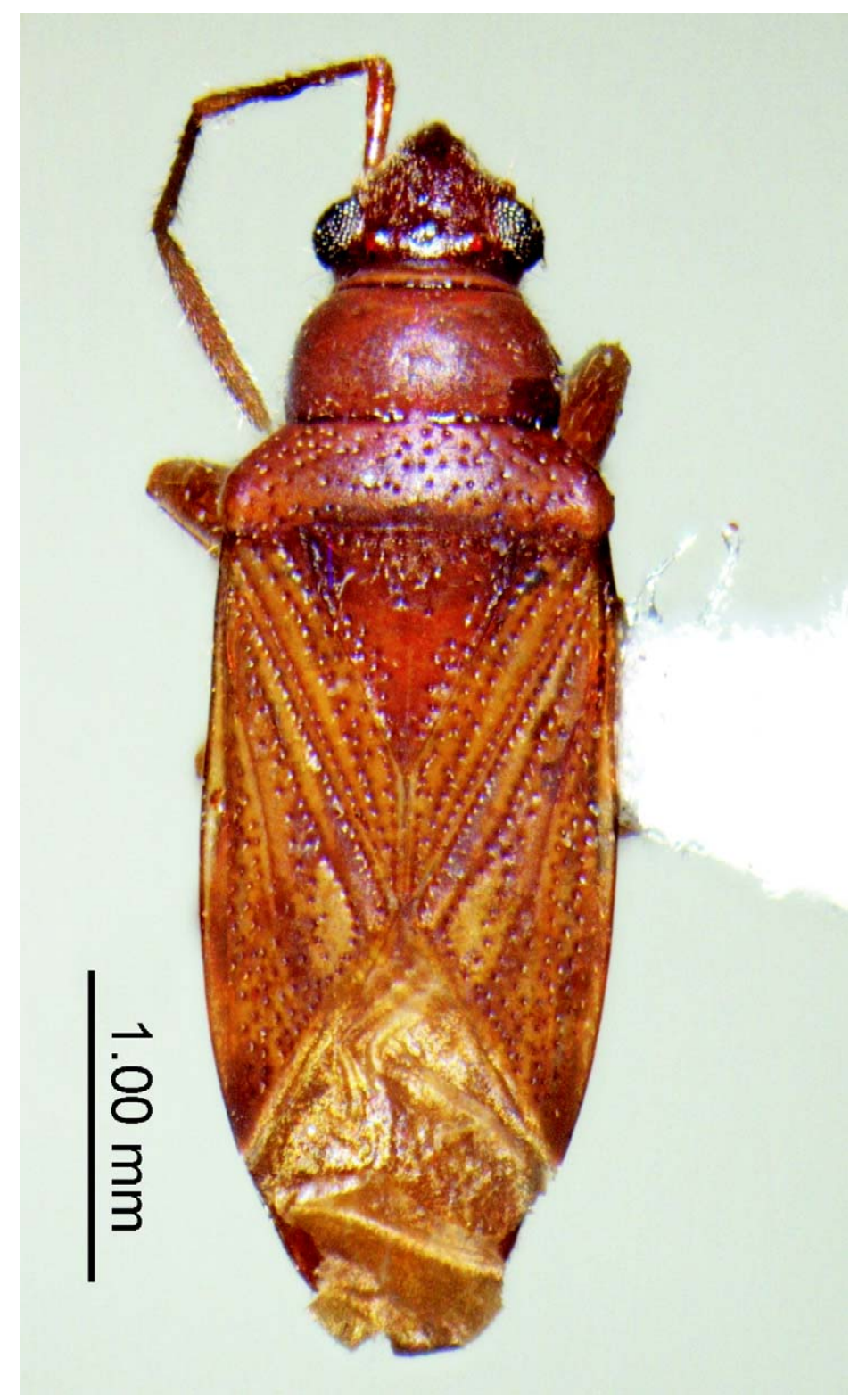

FIGURES 12. Remaudiereana castanea, holotype male,, body, dorsal view.

Head with abundant short silvery anteriorly decumbent setae, head length 0.62 , postocular distance 0.06; head width across eyes 0.74 , interocular space 0.42 ; interocellar space 0.29 . Antennae with semierect and erect setae, and abundant short decumbent setae on segment IV, length antennal segments, I 0.42, II 0.66, III 0.50, IV 0.73 . Length labial segments: I 0.53 , II 0.53 , III 0.36 , IV 0.30 . 
Pronotum with collar ringlike, anterior lobe impunctate and with transverse impression as a punctate furrow, shallow medially; posterior pronotal lobe with dense punctures; pronotal length 0.87 (collar length medially 0.06 , anterior pronotal length without collar 0.43 , posterior pronotal length 0.37 ), anterior pronotal lobe width 0.88 , posterior pronotal lobe width 1.28 , collar width 0.64 . Scutellum punctate, except on a slightly raised Y-shaped carina, length 0.76 , width 0.68 . Length hemelytra 2.62 , length corium 2.05 . Legs with procoxae armed with a spine; profemora with a few spines, outer row with only a large spine on distal $2 / 3$, inner row with three small spines apically, the proximal larger; protibiae straight, unarmed.

Pygophore in dorsal and lateral views as in figures 13-14. Paramere as in figures 15-16. Aedeagus unspined, phallotheca slightly pigmented, ejaculatory reservoir as in figure 17.

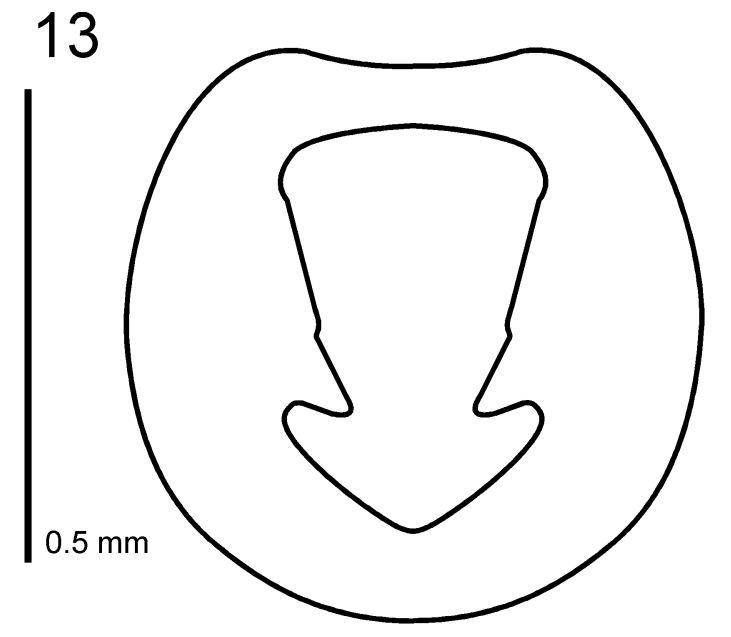

15

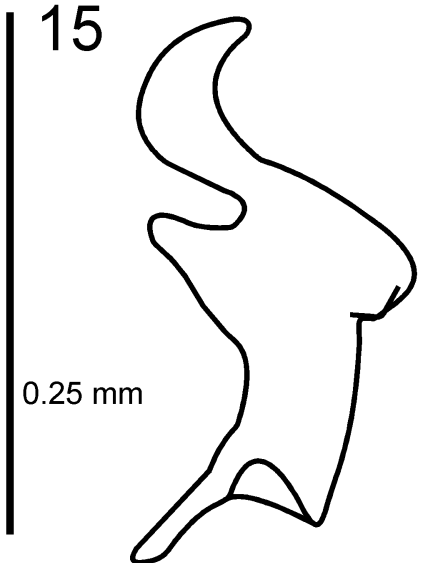

14

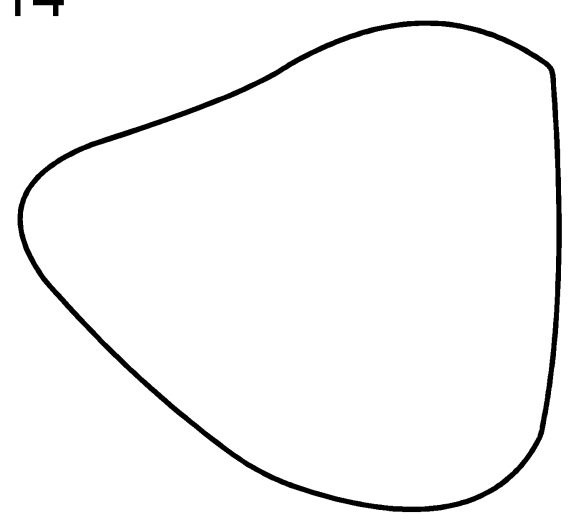

17
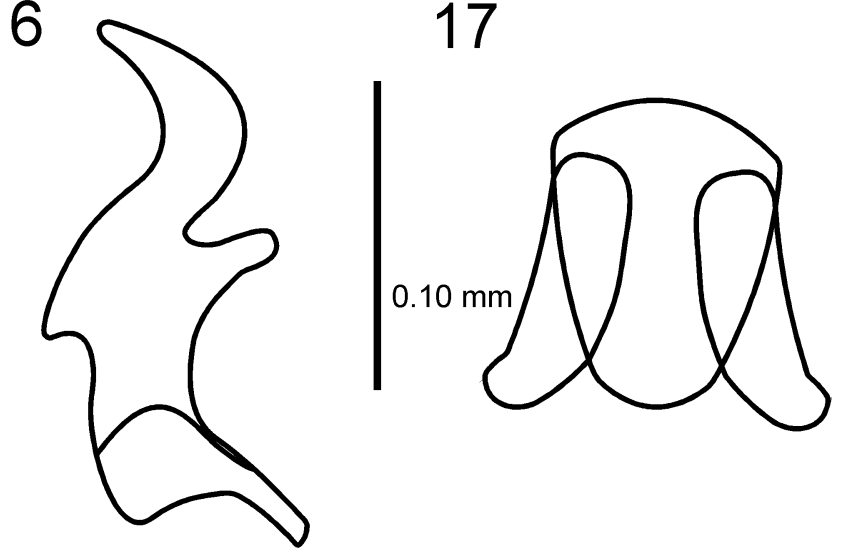

FIGURES 13-17. Remaudiereana castanea, holotype male: (13) pygophore, dorsal view; (14) pygophore, lateral view; (15) right paramere, inner view; (16) right paramere, outer view; (17) ejaculatory reservoir.

\section{Comments about the systematic placement of Remaudiereana castanea (Van Duzee)}

The specimen lacks the large spine at the midlength on the curved male protibiae, mentioned as diagnostic to the genus by Harrington (1980). Traditionally the presence or absence of spines on the protibiae of males was considered a distinctive character at the generic level, although intrageneric variation was reported in the genera Ashlockobius Slater \& Slater (Dellapé, 2003; Dellapé \& Montemayor, 2011) and Paisana Dellapé (Dellapé 2008). Malipatil (1978) noted an intraspecific variation for $R$. puberula with a male protibiae straight and unarmed, occasionally shallowly curved in the middle, and armed with 1-4 tuberculate, minute, irregularly spaced spines on the distal half. Despite lack of a large spine at midlength on the curved male protibiae, mentioned as diagnostic to the genus by Harrington (1980), this species was placed in Remaudiereana by Harrington (1980).

The morphology of the male genitalia is very similar to R. puberula (China), as illustrated by Malipatil (1978). The similarities in the morphology of male genitalia in several species of Remaudiereana Hoberlandt that have 
male foretibia either armed with one spine or unarmed, suggest that this character is variable within the genus (Malipatil, 1978).

The almost glabrous body surface of $R$. castanea is the most conspicuous character to separate it from $R$. puberula, which exhibits abundant pilosity.

\section{Acknowledgements}

We thank Dr. Shepherd Myers (Department of Natural Sciences, Bishop Museum) for the loan of the specimens, and Dr Mark Blacket for habitus images of Neocnemodus mumfordi.

\section{References}

Brailovsky, H. \& Cervantes-Peredo, L. (2011) New genus, new species and new records of Mexican Lygaeoidea (Hemiptera: Heteroptera). Studies on Neotropical Fauna and Environment, 46, 197-201.

Dellapé, P.M. (2003) A new species of Ashlockobius (Heteroptera: Rhyparochromidae: Myodochini) from Venezuela. Zootaxa, $289,1-6$.

Dellapé, P.M. (2005) Redescription of Paromius procerulus (Berg) (new combination) (Heteroptera: Rhyparochromidae: Myodochini), and description of eggs and immature stages. Zootaxa, 1070, 49-60.

Dellapé, P.M. (2008) Paisana: A new genus of Neotropical Rhyparochromidae (Hemiptera: Heteroptera: Lygaeoidea) to accommodate Neopamera brachialis (Stål) and four new species. Zootaxa, 1958, 17-30.

Dellapé, P.M. \& Henry, T.J. (2010) Acrolophyses, a new seed bug genus and two new species (Hemiptera: Heteroptera: Rhyparochromidae: Myodochini) from forest-canopy fogging in Ecuador and Peru. Insect Systematics and Evolution, 41, 75-89.

Dellapé, P.M. \& Montemayor, S.I. (2011) On the identity of Ashlockobius Slater \& Slater and Villalobosothignus Brailovsky (Hemiptera: Heteroptera: Rhyparochromidae: Myodochini), with the description of a new arboreal species from Ecuador. Zootaxa, 2748, 47-52.

Harrington, J. (1980) A generic level revision and cladistic analysis of the Myodochini of the world (Hemiptera, Lygaeidae, Rhyparochrominae). Bulletin of the American Museum of Natural History, 167, 49-116.

Malipatil, M.B. (1978) Revision of the Myodochini (Hemiptera: Lygaeidae: Rhyparochrominae) of the Australian region. Australian Journal of Zoology, Supplementary Series, 56, 1-178.

Scudder, G.G.E. (1970) The world Rhyparochrominae (Hemiptera: Lygaeidae) X. Further systematic changes. Canadian Entomologist, 102, 98-104.

Slater, J.A. (1964) A catalogue of the Lygaeidae of the world. University of Connecticut, Storrs, 2 vols, 1668 pp.

Slater, J.A. \& O'Donnell, J.E. (1995) A catalogue of the Lygaeidae of the world (1960-1994). New York Entomological Society, New York, $410 \mathrm{pp}$.

Van Duzee, E.P. (1932) New Hemiptera-Heteroptera from the Marquesas. Bishop Museum Bulletins, 98, 177-191.

Van Duzee, E.P. (1935) Note on Ptochiomera caeca Van Duzee. The Pan-Pacific Entomologist, 11, 174. 